\title{
Expected benefits of people interactions and guest experiences
}

\author{
Ya-Ling Chen \\ Department of Recreation and Leisure Studies, \\ State University of New York at Brockport, Brockport, New York, USA \\ Joseph Chen \\ Department of Health and Wellness Design, Indiana University Bloomington, \\ Bloomington, Indiana, USA \\ Wan-Yu Liu \\ Department of Forestry, National Chung Hsing University, Taichung, Taiwan, and \\ Tanmay Sharma \\ Department of Health and Wellness Design, Indiana University Bloomington, \\ Bloomington, Indiana, USA
}

\begin{abstract}
Purpose - This research aims to grasp hotel guests' motives and potential benefits sought when interacting with other guests, service personnel and residents and examines how these benefits can contribute to the total guest experience.

Design/methodology/approach - Mixed methods are adopted for the purpose of this study comprising individual interviews and a questionnaire survey.

Findings - Five groups of advantages emerge from individual interviews, including friendliness in interaction, social benefits, information acquisition, curiosity gratification and hospitality services. In the survey, which gathers 326 questionnaires, this study reveals that the five types of benefits derived from hotel guests' interactions could be further categorized into two dimensions: civility (e.g. friendliness and social) and utility (e.g. information, curiosity and service). The study confirms that four out of five potential or expected benefits from this personal interaction is significantly associated with the total hotel experience.

Research limitations/implications - Respondents of this study are culturally homogenous; as a result, multi-cultural settings should be considered for future research.

Originality/value - Tourism and hospitality literature on people's interaction is mostly center around social aspects of interaction. The current study comprehensively explores all expected utilities of interaction, occurring in all sorts of interactions (e.g. customer-to-resident and customer-to-service personnel). Specifically, the findings of this study uncover the underlying factors which prompt the tourists to interact with other people in a lodging setting and examine the relative importance of those underlying factors to the total lodging experiences.
\end{abstract}

Keywords Benefits sought, People-to-people interaction, Guest experiences, Mixed method

Paper type Research paper

\section{Introduction}

Seeking an optimal experience is an integral part of a tourist activity. Hence, it is not unusual that considerable attention has been paid to the conceptualization of the tourist experience. Seminal experience studies in sociology explored the phenomenon of individuals' trip

(C) Ya-Ling Chen, Joseph Chen, Wan-Yu Liu and Tanmay Sharma. Published in International Hospitality Review. Published by Emerald Publishing Limited. This article is published under the Creative Commons Attribution (CC BY 4.0) licence. Anyone may reproduce, distribute, translate and create derivative works of this article (for both commercial and non-commercial purposes), subject to full attribution to the original publication and authors. The full terms of this licence may be seen at http:// creativecommons.org/licences/by/4.0/legalcode.

\section{People interactions and guest experiences}

Received 13 April 2020

Revised 24 June 2020

30 June 2020

Accepted 30 June 2020 
IHR

34,2

188

engagement. In sociology, two schools of thoughts emerged during the early stages of experience studies: the first relates to MacCannell's authenticity concept (1973) that discusses tourists' aspirations regarding authenticity in their expeditions and Cohen (1979) represents the second sociological camp that delineates tourist behaviors via a typology approach that illustrates five experience continuums. Further, the psychological literature (e.g. Csikszentmihalyi, 1990; Csikszentmihalyi and LeFevre, 1989; Mannell and Iso-Ahola, 1987) has revealed the subjective nature of tourist experience. Mannell and Iso-Ahola (1987) described tourist experiences as an interplay between the need to escape routine or stressful environments and to seek intrinsic rewards. One of the rewarding experiences is to mingle with tourists who have never met and learn new refreshing perspectives via the conversation. Indeed, such people interaction could engender a positive tourist experience (Papathanassis, 2012). Nevertheless, the hospitality and tourism literature on people's interaction is sporadic, as presented in Table 1, and those studies seemingly center on social aspects of interaction. Since the purpose of people-to-people interaction is more than social function, it is plausible to examine the underlying benefits of people interaction in a systematic way.

\section{Purpose of the study}

In the spirit of advancing current theories and professional practices, it seems advantageous to expand the investigative horizon of people's interaction by comprehensively exploring all expected utilities of interaction occurring in all sorts of interactions (e.g. customer-to-resident, customer-to-service personnel). From this viewpoint, this study posits to examine the underlying utilities of people interaction, based on concepts derived from the tourist experience driver model by Chen et al. (2014), embracing tourist-to-tourist (= customer-tocustomer), tourist-to-service personnel (= customer-to-service personnel) and tourist-toresident (= customer-to-resident) interaction. Consequently, two research objectives are developed to accomplish the study's aim: (1) to uncover the underlying factors which prompt the guests to interact with other people in a lodging setting and (2) to examine the relative importance of those underlying factors to the total guest experiences. The first objective attempts to build a theoretical battery of expected benefits of people interaction, which may be further utilized in theory development. The second objective strives to assess the

\begin{tabular}{|c|c|c|c|}
\hline Year & Author & Typology of interaction & Setting \\
\hline 2006 & Zhang et al. & Customer-to-resident & Destination city \\
\hline 2007 & $\mathrm{Wu}$ & Customer-to-customer & $\begin{array}{l}\text { International } \\
\text { travel }\end{array}$ \\
\hline 2009 & Huang and Hsu & Customer-to-customer & Cruise ship \\
\hline 2010 & Huang and Hsu & Customer-to-customer & Cruise ship \\
\hline 2010 & Levy & Customer-to-customer & $\begin{array}{l}\text { Cultural heritage } \\
\text { tour }\end{array}$ \\
\hline 2011 & Armensk et al. & Customer-to-resident & Destination city \\
\hline 2012 & Papathanassis & Customer-to-customer & Cruise ship \\
\hline 2013 & Wu et al. & Customer-to-customer & Leisure trip \\
\hline 2014 & Choo and Petrick & $\begin{array}{l}\text { Customer-to-customer, customer-to-service personnel } \\
\text { and customer-to-resident }\end{array}$ & Farm \\
\hline 2016 & Chen et al. & $\begin{array}{l}\text { Customer-to-customer, customer-to-service personnel } \\
\text { and customer-to-resident }\end{array}$ & Attraction \\
\hline 2018 & $\begin{array}{l}\text { Capistrano and } \\
\text { Weaver }\end{array}$ & Customer-to-resident & $\begin{array}{l}\text { International } \\
\text { travel }\end{array}$ \\
\hline 2018 & $\begin{array}{l}\text { Kriwoken and } \\
\text { Hardy }\end{array}$ & Customer-to-customer & Cruise ship \\
\hline 2019 & Lin et al. & Customer-to-customer & Day trip \\
\hline
\end{tabular}

Hospitality/tourism literature covering people interaction in the last decade (from 2006 to present) 
underlying relationship between the expected benefits of interaction and customer service experiences. The outcomes of the study may allow industry professionals to strategize plans for service delivery and product development.

\section{Literature review}

\section{Tourist experiences}

From a management perspective, Otto and Ritchie (1996) discovered that tourist experiences might be represented by four domains: hedonics, peace of mind, involvement and recognition. Even though service quality has been established within its conceptual and empirical foundation to support service marketing in the tourism industry (Carman, 1990; Parasuraman et al., 1988), Otto and Ritchie (1996) categorized service quality and experiences under different measurements and frameworks due to the subjectivity of the tourism experience.

Likewise, in the context of experience in marketing management, Schmitt (1999) suggested experience marketing as an emerging phenomenon outside of goods and services marketing, using "strategic experiential modules" that includes (1) sensory experiences, (2) affective experiences, (3) creative and cognitive experiences, (4) physical experiences, behavior, and lifestyles and (5) social-identity experiences that result from being related to a reference group or culture, which allows managers to create different types of customer experiential opportunities when incorporating new services or products.

Evaluating the various dimensions of the tourist experience, Pine and Gilmore (1999) added a framework for experience economy for understanding and assessing experiential consumption. These realms of tourist experiences conveyed the rise of consumer demand for exalted or beneficial service experience. Moreover, scholars have developed quantitative assessment tools to measure individuals' experiences and touch on this notion of the experience economy. The Consumer Experience Index (Knutson et al., 2006; Kim et al. (2012)), for example, utilizes seven experience dimensions (i.e. environment, benefits, convenience, accessibility, utility, incentive and trust) to gauge the service experience.

Beyond the conceptualization of tourist experiences, some studies have focused on specific experiential consumption such as backpacking (Uriely et al., 2002), sports (Bouchet et al., 2004), food (Quan and Wang, 2004) and culture (Prentice, 2001). Additionally, studies also explored methodologies seeking to reveal tourist experiences, for instance, Volo (2010) proposed online travel blogs as a valuable data source for experience research, and Matteucci (2013) utilized photo-elicitation as a creative way to capture tourist experiences. Researchers have also touched on scale development to measure trip experiences, wherein Kim et al. (2012) examined recallable trip experiences to determine how a tourist experience evoked positive and negative memories.

Most recently, a new stream of literature investigates what constitutes the creation of memorable experiences (e.g. Kim and Chen, 2019; Kim et al., 2012) and how to engage tourists to collaborate in the cocreation of such experiences (Prebensen et al., 2014). As part of the cocreation literature, a model of factors that impact tourist experiences proposed by Chen et al. (2014) depicts the processes involved in tourist experience formation. This model, titled "Tourist Experience Driver Model” (TEDM), consists of trip-partaking experiences (before and during the trip) and trip reminiscing experiences (after the trip). It argues that three types of drivers could affect the trip-partaking experience: personal, environmental and interactive. The model further categorizes the reminiscing trip experience as being part of nonrecallable or recallable experiences, where the recallable experience can be placed into five typologies: disastrous, regretful, monotonous, memorable and extraordinary experiences. Chen et al. (2014) postulated that interactive drivers could augment tourists' excitement about a destination and potentially lead to a positive trip experience, such as when engaging in tourist-to-tourist interactions and tourist-to-service staff interactions. 
IHR

34,2

190

\section{People-to-people interaction}

Empirical studies on tourist experiences have sufficiently supported the significance of the people interactions. For example, studies by Kim et al. (2012), Morgan and Xu (2009) and Kim and Chen (2019) indicated that encountering locals is one of the components promoting memorable tourist experiences. Meng et al. (2008) identified friendliness of personnel as one of the critical factors affecting the tourist experience, and Mossberg (2007) claimed that encounters with service personnel and other tourists serve to modify the tourist experience. In service encounter research, a plethora of studies have touched on issues relevant to customer interactions, including parties involved in the interaction such as customer-to-customer (C-toC) (Grove and Fish, 1997), the moderator of interaction such as customer homogeneity (Levy, 2010; Wu et al., 2013), the mediating effects (i.e. cohesion and intimacy) on tourist experiences (Lin et al.,2019) and satisfaction and dissatisfaction as an outcome of interactions exemplified by the customer-to- customer relationships in service encounters (Martin and Pranter, 1989).

As adequately established in the literature, service encounters, involving the customer, service personnel, physical environments and other customers, are considered temporary, discrete activity (Surprenant and Solomon, 1987) and could shape customer's evaluation of service experiences (Martin and Pranter, 1989).

Focusing on the social aspect of interaction, Liu et al. (1987) suggested that interactions between tourists and residents bolster the residents' positive attitudes toward tourism development. Similarly, in their examination of value perception in relationship-to-people interaction, Chen et al. (2016) discovered that social value affects people's interaction. Zhang et al. (2006) pinpointed that resident's attitudes toward tourist-host interaction may be influenced by personality and ethnicity. Reisinger and Turner (1998) regarded cultural background as another moderator impacting people interaction and acknowledged the role of cultural differences between Asian tourists and Australian hosts as a predictor of their social interaction and satisfaction. Furthermore, Armenski et al. (2011) proposed that tourist's interaction with locals also shapes tourist's perceptions of the destination. Service encounters allow buyers and sellers to negotiate the terms of exchanging relationships (Czepiel, 1990), helping to open up a channel for establishing long-run relationships.

In addition to interactions between customers and service personnel, the phenomenon of C-to-C interactions has recently been the focus of service encounter research in tourism. Researchers have identified several vital variables that facilitate optimal service experience encounters by promoting C-to-C interaction, such as customer compatibility and behavioral conformity. Customers are more likely to interact with identical demographics and shared value beliefs (Martin and Pranter, 1989; Martin, 1995). Wu (2007), in a survey of outbound travelers, stated that during $\mathrm{C}$-to-C interactions, customer homogeneity contributes to customer satisfaction and that service evaluation from fellow customers has a positive influence on customer satisfaction. Huang and $\mathrm{Hsu}(2010)$ further confirmed that the quality of C-to-C interaction could influence trip satisfaction.

Even though people-to-people interaction is an essential part of the total tourist experience, individuals may pose a different level of desire to interact with others in different travel circumstances. Papathanassis (2012) discussed the barriers to interaction in a C-to-C setting and suggested that presence (or absence) of cultural compatibility between socially interacting consumers could impact the continuation of social interactions. For example, Murphy (2001) found that backpackers are motivated to interact with fellow backpackers to socialize and to undertake destination information inquiry and interpretation. These social interactions result from the initial screening that culminates into an intentional identification of a compatible cohort of travelers with shared routines and experiences, leading to subsequent positive exchanges. Moreover, Choo and Petrick (2014) uncovered that tourists entering different destinations, such as a farm, are inclined to interact with people living in the surroundings to enhance their trip experience and satisfaction. 


\section{Methodology}

Since no existing scale measures the expected benefits of people interaction, this study deployed a mixed method approach, consisting of personal interviews and questionnaire surveys, to construct measurement items. It is a sequential exploratory design that involves two phases of data collection: qualitative methods (i.e. personal interview) followed by a quantitative tool (i.e. survey research). The second phase data collection builds upon the results of the first qualitative results (Creswell, 2009). The purpose of the interview was used to inform the questionnaire survey. Specifically, personal interviews attempted to determine the underlying tourist's expected benefits of people interactions, such as tourist-to-server and tourist-to-tourist interactions. The mixed method approach has been an established design of research in social sciences. For example, Kim and Chen (2019), probing the concept of the memorable travel experience, deployed a mixed method which first evoked five dimensions elucidating the memorable travel experience through personal interviews and subsequently deployed questionnaire surveys to confirm/disconfirm the resultant dimensions by using a confirmatory factor analysis (CFA).

The study site Hangzhou, China is ranked among the top-10 travel destinations due to its historical and heritage attractions (Travel China Guide, 2015). The city is located in the Zhejiang Province, which has 11 national-level scenic areas (e.g. West Lake, Fuchun River, Xinan River and ThousandIsland Lake) and 35 province-level beautiful spots (China Information Center, 2015). Hangzhou is the provincial capital and the region's political, economic and cultural center. For data collection, 16 personal interviews, including seven hotel guests and nine hotel employees represented by hotel managers and staff, were conducted at hotel lobbies with a timeframe of 15-25 minutes. As Creswell (1998) suggested a sample number from 5 to 25 as adequate for a phenomenological stud, the 16 interviews were deemed to be sufficient. During the interviews, participants shared their perspectives on expected benefits derived from interacting with others by responding to the question of "what kind of benefits do you expect from interacting with others at hotels?" Data analysis followed the procedures suggested by Creswell (2009) comprising raw data transportation, organizing and preparing data analysis, reading through all data, coding the data, generate themes, interrelating themes and interpreting the meaning of the themes. After transcribing the interview data, a thematic analysis was deployed, which revealed five expected-benefit dimensions: (1) friendliness, (2), social (3) information, (4), curiosity and (5) service. It is essential to distinguish between the dimensions of information and service benefits, which involve information acquisition. However, as the service dimension deals with service-related information acquisition, the aspect of information denotes the expected or potential benefits derived from information searches not related to hotel services.

After the interviews, a structured questionnaire was developed, wherein each benefit dimension was further assessed by five questions using a seven-point Likert-type scale from 1 (strongly disagreed) to 7 (strongly agreed). The questionnaire, thus, included a benefit scale as the key research variable, explicated by 25 indicators. A pilot study was conducted on 30 hotel guests to screen the scale reliability. As a result, the Cronbach's alpha score was calculated as being 0.86 , which showed that no item deleted from the scale would significantly improve its reliability. Subsequently, a series of onsite surveys were conducted at seven upscale hotels in the city of Hangzhou. In this questionnaire survey, the respondents comprised hotel guests who were approached in the hotel lobby, café and restaurant. Respondents were approached and either asked to complete a hard-copied survey or asked questions verbatim by the researcher.

Mean analysis was used to determine the relative importance of benefit indicators. In the process of validating the measurement scale concerning the expected benefits of personal interaction, CFA was deployed. Brown (2006) indicated that higher-order factor analyses could produce a more parsimonious account for the correlations among lower-order factors.

\section{People interactions and guest experiences}


IHR

34,2

192

The qualitative approach suggested that the five benefit factors may be further combined into two second-order categories: civility and utility. The reason for this approach was that the interaction benefits dealing with information, service and curiosity tend to be a function of utility, whereas friendliness and social benefits are apt to be driven by a sense of civility. A second-order factor analysis was performed to determine whether these two second-order factors could be proved statistically. Lastly, this study conducted regression analyses to test the effects of benefit factors on the total lodging experience, which was assessed by the question of "the experiences of interacting with others (such as service staff, other guests or local people) enhances my lodging experience in general."

\section{Results}

Descriptive data analyses

Stemming from the 326 useful questionnaires collected, Table 2 shows the profile of respondents. In total, $60.8 \%$ of respondents were female; $53.1 \%$ had a bachelor's degree and $56.7 \%$ were aged below 26 to 45 . The mean scores of all 25 benefit attributes (Table 3 ) showed that the two highest means over 6.0 were (1) timely response $(M=6.09)$ and (2) destination information $(M=6.05)$. Among the five dimensions, the information domain represented the highest composite mean $(M=5.86)$, followed by social $(M=5.61)$, friendliness $(M=5.59)$, whereas curiosity $(M=5.4)$ and service $(M=5.4)$ showed the lowest two dimensions. The results suggested that the guests' reaction to information inquiry is a key driver for people's interaction. Although nowadays, a large amount of travel data can be quickly retrieved by hotel guests via electronic devices, including cell phones, tablets and computers, hotel guests fully appreciate face-to-face personal interactions as an effective channel to fulfill their information need. Further, the lowest mean concerning the perceived benefits of personal interaction is the guests' desire to make complaints $(M=4.90)$. The reliability of the benefit scale is evident in the Cronbach's alpha score of 0.95 , wherein all 25 benefit indicators can collectively assess the benefits of personal interaction.

\section{Confirmatory factory analysis}

A confirmatory factor analysis (CFA) was performed to determine if the 25 indicators could accurately measure the perceived benefits of personal interaction in a hotel setting with a five-

\begin{tabular}{lll}
\hline Characteristics & Sample & \\
& $N$ & $\%$ \\
\hline Total & 326 & \\
Gender & & 39.2 \\
Male & 123 & 60.8 \\
Female & 191 & \\
Education level & & 13.3 \\
High school & 43 & 24.7 \\
2-year college & 80 & 53.1 \\
4-year college & 172 & 9 \\
Graduate school & 29 & \\
Age & & 56.7 \\
18-25 & 88 & 15.3 \\
26-45 & 185 & 0.9 \\
46-65 & 50 &
\end{tabular}

Table 2.

Demographic

characteristics 
Friendliness

I feel at home when interacting with other people. (=home)

The environment encourages me to interact with other people. (=encouragement)

I feel it is necessary to interact with others when I am in a friendly atmosphere. (=necessity)

A friendly environment excites me to talk with others. (=excitement)

Social

I want to approach people surrounding me. (=approaching)

I feel encouraged to talk to the people around me if they are nice to me. (=people)

I want to make friends when traveling. (=friend)

Interacting with others makes me feel happy. (=joy)

I want to get close with people and the environment surrounding me. (=closeness)

\section{Information}

I need information about destinations I have visited on this trip. (= destination)

I expect timely responses to problem I have faced when traveling. (=response)

I want to learn something new from others. (=learning)

I want to get familiar with the environment where I visit. (=familiarity)

I want to find the best answers as possible to resolve my uncertainty. (=uncertainty)

\section{Curiosity}

I am curious about the people I have encountered when traveling. (=encounter)

I want to know other people's personal stories. (=stories)

I want to know what is happening within destination communities. (=community)

5.35

I want to get familiar with the artifacts, histories and people at the destinations. (=artifacts) 5.81

I want to learn local culture. (=culture)

\section{Service}

I am likely to make service related complaint(s) to others when traveling. (=complaint) 4.90

I like face-to-face interaction with service staff. (=contact) $\quad 5.27$

Because there is a sufficient number of service staffs, I feel I could better utilize them by asking any $\quad 5.36$ questions of interesting. (=adequacy)

Service staffs are generally able to resolve my service concerns immediately. (=concern)

Table 3.

Mean scores of expected benefits derived from people interaction

dimension solution, and IBMSPSS Amos 25 was utilized as an analysis tool. The significance of the five-dimension model was determined by a chi-square ratio and the fit indexes of the comparative fit index (CFI), adjusted goodness of fit (AGFI), and root mean square error of approximation (RMSEA). The proposed model (Figure 1) contained five benefit dimensions explained by 25 indicators. In the model (Model A) test, the results revealed an unsatisfactory model fit $\left(x^{2}=871.72, \mathrm{df}=265, x^{2} / \mathrm{df}=3.29, \mathrm{CFI}=0.856, \mathrm{AGFI}=0.798, \mathrm{RMSEA}=0.084\right)$.

After deleting five indicators of necessity, encounter, stories, complaint and attention from the initial model, a revised model (Model B) represented an improved model $\left(x^{2}=410.53\right.$, $\left.\mathrm{df}=158, x^{2} / \mathrm{df}=2.6, \mathrm{CFI}=0.932, \mathrm{AGFI}=0.840, \mathrm{RMSEA}=0.07\right)$. Items were deleted due to low regression weight, and concerns and attention were eliminated in consideration of convergent validity.

\section{The final CFA model}

In sum, the final model included 20 indicators explaining five first-order benefit factors. Three to five indicators, respectively, illustrated the five benefit dimensions. The structure of the five-dimension model was categorized explicitly as (1) friendliness (e.g. home, encouragement, benefits and excitement), (2) social (e.g. approaching, people, friends, joy and closeness), (3) 
IHR

34,2

194

Figure 1.

Original/

hypothetical model

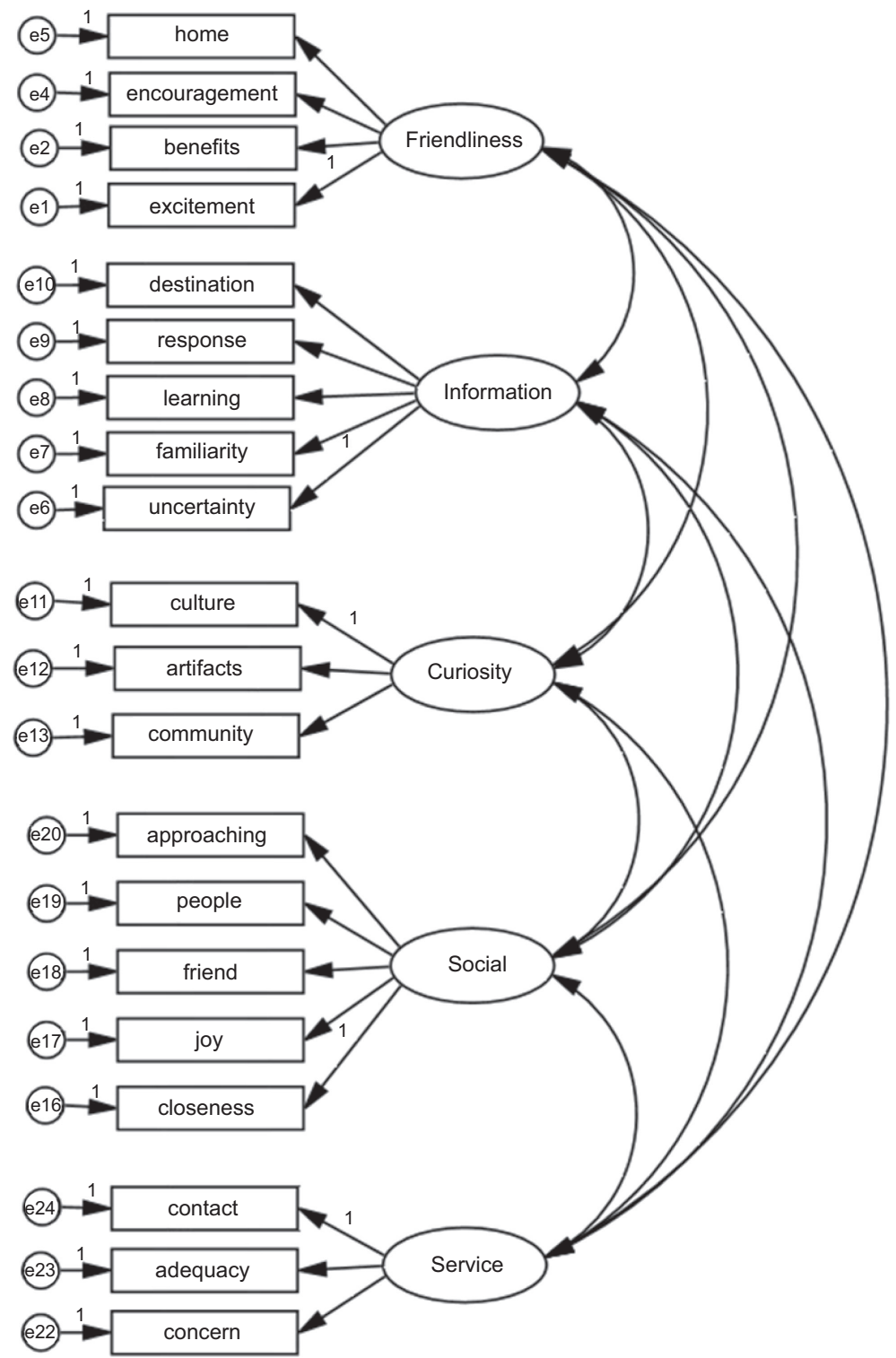

curiosity (e.g. community, artifacts and culture), (4) information (e.g. destination response, familiarity and uncertainty) and (5) service (e.g. contact, adequacy and concern) (Table 4).

This study examined the scale reliability involving (1) composite reliability (CR) and (2) the percentage of average variance extracted by each construct (AVE). In the final model of the study, all composite reliability scores were above 0.70 , while the AVE measures ranged between 0.48 and 0.66 . Hatcher (1994) proposed composite reliability higher than 0.70 and AVE over 0.50 ; hence, the results of this study indicated satisfactory scale reliability. A validity test was performed to see if the underlying construct measuring the concept (benefits 
of interaction) proposed by this study was accurate. The convergent validity of the scale (Table 5) was also acceptable, as evidenced by high path coefficient scores $(>0.50)$ except the service dimension, which showed a marginal value (0.48).

Second-order factor analysis

A second-order factor analysis performed presented five first-order factors (e.g. friendliness, social, information, curiosity and service) and two second-order factors (e.g. civility and utility). The results (Table 6 ) showed a satisfactory model $\left(x^{2}=431.15, \mathrm{df}=161, x^{2} / \mathrm{df}=2.68\right.$, $\mathrm{CFI}=0.927$, AGFI $=0.829$, RMSEA $=0.072$ ) indicating that friendliness and social dimensions contributed to a second-order factor labeled as civility, while information, curiosity and service served as the second-order factor utility (Figure 2).

\begin{tabular}{lcccccc}
\hline Model & $x^{2}$ & $d$ & $x^{2} /$ df & CFI & AGFI & RMSEA \\
\hline Model A $^{\mathrm{a}}$ & 871.72 & 265 & 3.29 & 0.856 & 0.798 & 0.084 \\
Model B $^{\mathrm{b}}$ & 410.53 & 158 & 2.6 & 0.932 & 0.840 & 0.07
\end{tabular}

Note(s): ${ }^{\text {a }}$ Model A = the original model containing 25 indicators. Each benefit dimension has five indicators; ${ }^{\mathrm{b}}$ Model B = a competing model, deleting indicators necessity, encounter, stories, complaint and attention from the original pool of indicators, with 20 indicators

\section{People interactions and guest experiences}

195

\begin{tabular}{|c|c|c|c|c|}
\hline Dimensions and indicators & Path coefficient & $\mathrm{CR}^{\mathrm{a}}$ & $\mathrm{AVE}^{\mathrm{b}}$ & \\
\hline 1. Friendliness & & 0.83 & 0.56 & \\
\hline Home & 0.63 & & & \\
\hline Encouragement & 0.72 & & & \\
\hline Benefits & 0.76 & & & \\
\hline Excitement & 0.86 & & & \\
\hline 2. Social & & 0.84 & 0.53 & \\
\hline Approaching & 0.61 & & & \\
\hline People & 0.71 & & & \\
\hline Friend & 0.79 & & & \\
\hline Joy & 0.89 & & & \\
\hline Closeness & 0.84 & & & \\
\hline 3. Information & & 0.79 & 0.57 & \\
\hline Destination & 0.74 & & & \\
\hline Response & 0.68 & & & \\
\hline Learning & 0.59 & & & \\
\hline Familiarity & 0.83 & & & \\
\hline Uncertainty & 0.79 & & & \\
\hline 4. Curiosity & & 0.88 & 0.66 & \\
\hline Culture & 0.84 & & & \\
\hline Artifacts & 0.89 & & & \\
\hline Community & 0.46 & & & \\
\hline 5. Service & & 0.73 & 0.48 & \\
\hline Contact & 0.71 & & & Table 5. \\
\hline Adequacy & 0.76 & & & Reliability of the \\
\hline Concern & 0.59 & & & $\begin{array}{l}\text { Rellabillty of the } \\
\text { resultant model on }\end{array}$ \\
\hline \multicolumn{4}{|c|}{ Note(s): ${ }^{\mathrm{a}} \mathrm{CR}$ : Composite reliability and ${ }^{\mathrm{b}}$ AVE: Average variance extracted } & benefits \\
\hline
\end{tabular}


IHR

34,2

196

\section{Regression analysis}

Lastly, regression analysis (Table 7) was conducted to evaluate the degree to which the benefit domains affect the total lodging experience. Concerning the high-order factors, both utility and civility were found to significantly affect the overall lodging experience $(p<0.01)$, where utility had a stronger impact on the total lodging experience. As for the five lower-order factors, only one factor, i.e. information, was not a significant predictor of the total lodging experience. Among the four benefit dimensions, service was the strongest predictor of the overall lodging experience, whereas curiosity was the least powerful predictor.

\section{Conclusion}

Given the void in the current literature regarding the expected benefits of people interaction, this study uses a mixed method approach to derive attributes that assess the benefits of interaction. The study first deploys a qualitative approach, which results in five streams of expected benefits associated with personal interactions; these consist of friendliness, social, information, curiosity and service by using hotels as the study setting. The benefit dimensions may be further grouped into two benefit categories: civility and utility. The results offer comprehensive insights into the benefits of people interactions in terms of guest-to-guest, guest-to-server and guest-to-locals. In brief, the revelation of the dimensions of the expected benefits of people interaction may be viewed as the distinct contribution of the study.

\section{Theoretical implications}

Notably, this study identifies the particular functional benefits of people interactions (i.e. utility and civility), which extends the coverage of Papathanassis (2012), who randomly articulated a limited number of functional benefits of guest-to-guest interaction as an example of interaction utility. Moreover, the presentation of the refined dimension labeled as civility may be viewed as an essential contribution to the literature and the hospitality industry. The existing research suggests that social interests serve as a vital aspect of the guest experience, encouraging guests to initiate interactions with all parties. The results shed new light on the subject, precisely, that beyond functional and social benefits, friendliness in terms of pleasant exchanges and social warmth could be considered as a critical driver for personal interaction, where friendliness and social factors seem to be intricately linked. For example, demonstrating friendly behavior reflects a "civilized" manner that functions as social mingling. From a holistic viewpoint, expanding upon the current literature that frequently reports social factor as an essential motor for people interaction, it is wise to redefine such intentions in the context of "civility," which seems to be an all-embracing descriptor in terms of theorizing a beneficial pillar of people interaction based on cultural and behavioral norms.

In the provision of generalizable findings, this research employs a questionnaire survey on high-end hotel guests resulting in a five-dimension model explained by 20 attributes. Also, the five dimensions as lower-order factors are merged into two domains, regarded as higherorder factors as presented in the structural model. In future research, the five-dimension scale could be utilized as an antecedent or moderator of different types of psychological traits, such as satisfaction and loyalty, for theory extension. For example, following the dynamic experience model by Chen et al. (2014), new scholarly undertakings may further test the extent to which the interactive drivers, such as people interaction, determine positive

Table 6.

Model fit indices from second-order factor analysis

\begin{tabular}{lcccccc}
\hline & $x^{2}$ & df & $x^{2} / \mathrm{df}$ & CFI & AGFI & RMSEA \\
\hline Second-order model & 431.15 & 161 & 2.68 & 0.927 & 0.829 & 0.072 \\
\hline
\end{tabular}




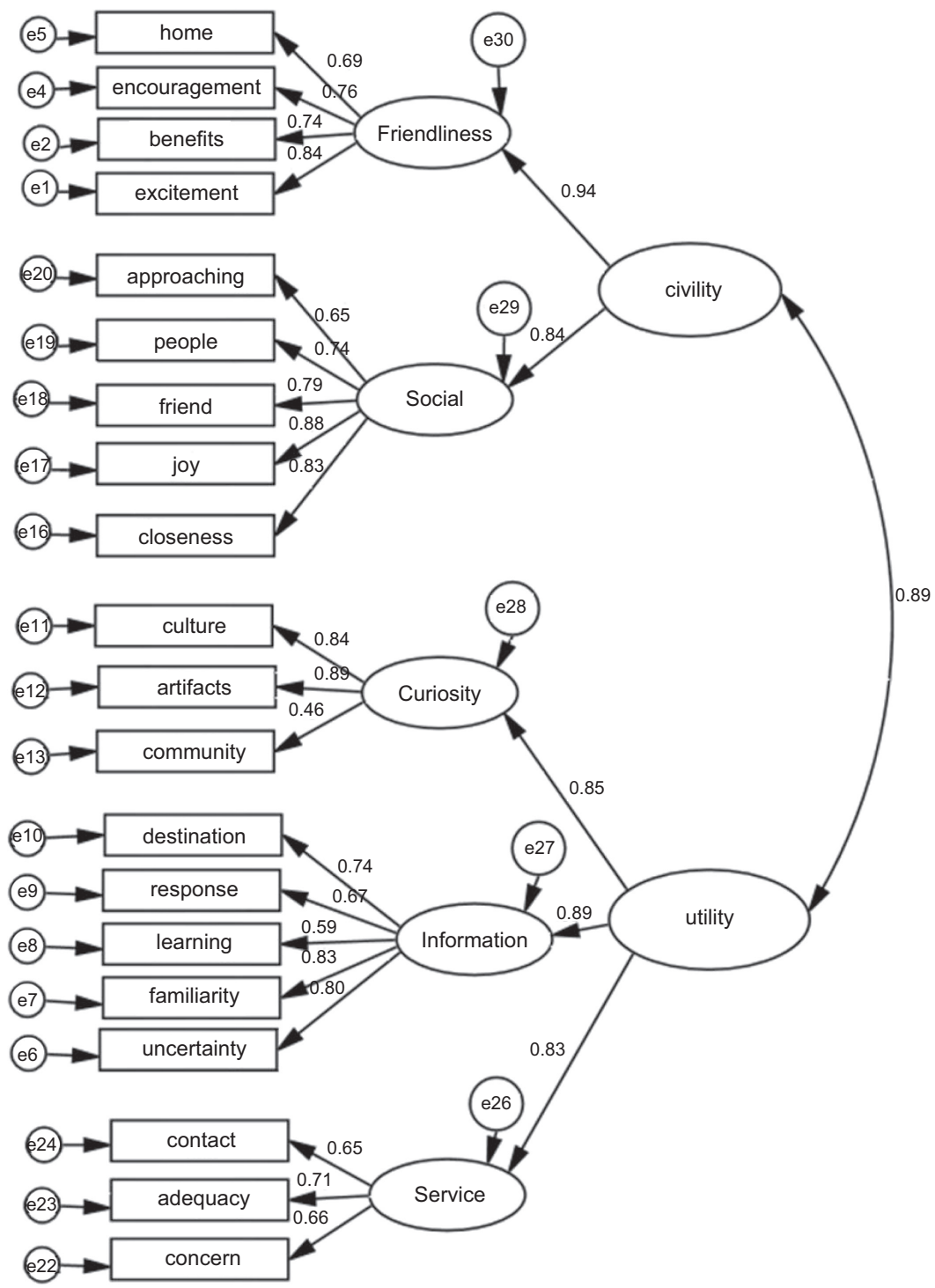

\section{People interactions and guest experiences}

Figure 2.

Resultant secondorder model

reminiscing outcomes (e.g. memorable and extraordinary experiences). Nevertheless, it is vital to recognize the constraints of this resultant model, wherein the dimension of service indicates marginal discriminant validity. Further research on people interaction may draw different samples or generate more indicators for the service dimension to boost up its validity in measurement.

\section{Managerial implications}

Concerning the casual relationship between the interaction benefits and the lodging experience, it appears that most benefits sought via people interaction could affect the overall 
IHR

34,2

198

experience. While the information search does not affect the total experience, this study finds that it is the most critical driver for encouraging hotel guests to engage with people in surrounding hotels. The following two facts led to these assumptions; first, the level of tolerance concerning guest satisfaction may be broad, as needed information is absent and that guests can retrieve relevant information on a destination via different avenues and methods, such as using computer/cell phones and giving a call to someone for consultation. Second, when engaging in personal interaction, the information that guests intend to search primarily deals with the hotel and surrounding destinations. To better facilitate the guests' information needs, hotel managers should offer high-speed, free Wi-Fi access to lobby areas and Internet-ready terminals. For those lodging accommodations with complimentary wireless access for their guests, it is essential to articulate how such a service should further provide better efficiency and speed of access.

This study finds that making complaints is the least important attribute for prompting hotel guests to interact with people. As the literature discloses (e.g. Kim and Chen, 2010), there are several ways to make complaints about hotel services. Talking to the service providers/ managers is the most direct way to solve service issues. It is not clear why the respondents weigh such an interaction benefit marginally, perhaps the cultural background of guests in upscale hotels, where all study participants are Chinese, demonstrates a high level of tolerance and risk avoidance (Hofstede, 1991). Alternatively, it could also be due to the prevalence of information technologies, using a third party (e.g. travel blogs) as a venue for making complaints that may be more productive and timely. The above discussions lead to the following managerial implications: hotel managers may proactively interact with their guests by offering some incentives (e.g. cash rewards and gifts), especially for those with a high level of tolerance or risk avoidance, an approach that allows the managers to close the potential service gaps in a timely, friendly and systematic manner.

Among the five dimensions generated from the model, service and friendliness emerge as the two most reliable predictors of total lodging experiences than other types of benefits. The result is in line with the current literature (e.g. Meng et al., 2008) articulating that guests highly value the friendliness of service staff, which influences their overall experiences. It again confirms that creating a friendly atmosphere for hotel guests ought to be a crucial task for hoteliers. Besides, it is not surprising to see that service-related benefits strongly affect the hotel guests' total lodging experiences. Indeed, through face-to-face interaction, guests are more likely to fulfill their service needs effectively.

Nevertheless, with the recent information technology revolution, consumers, especially the younger generations, have adopted a new lifestyle that involves electronic appliances and social media activities such as messaging, chatting and meeting conduits to foster people's interactions. What has transformed with respect to personal interaction is the change of interaction location (e.g. from onsite to e-channel) and the frequency of interaction, such as by

\begin{tabular}{lccccc}
\hline & $B$ & SE & $\beta$ & $t$ & $p$ \\
\hline $\begin{array}{l}\text { Second-order factors } \\
\text { Civility } \rightarrow \text { experience }\end{array}$ & 0.45 & 0.08 & 0.34 & 5.38 & $0.00^{*}$ \\
Utility $\rightarrow$ experience & 0.51 & 0.09 & 0.36 & 5.66 & $0.00^{*}$ \\
First-order factors & & & & & \\
Friendliness $\rightarrow$ experience & 0.38 & 0.07 & 0.31 & 5.17 & $0.00^{*}$ \\
Social $\rightarrow$ experience & 0.41 & 0.07 & 0.35 & 5.93 & $0.00^{*}$ \\
Information $\rightarrow$ experience & 0.13 & 0.08 & 0.07 & 1.54 & 0.12 \\
Curiosity $\rightarrow$ experience & 0.27 & 0.07 & 0.26 & 4.03 & $0.00^{*}$ \\
Service $\rightarrow$ experience & 0.45 & 0.07 & 0.37 & 6.90 & $0.00^{*}$ \\
& & & & &
\end{tabular}

Table 7.

Effects of people interaction on experiences 
e-messaging, for instance. It is important to consider incorporating information technology to promote customer-to-service personnel interaction. For example, a hotel service center may allow its guests to make an instant inquiry via text message or video call. The above suggestion may lead to a viable direction for future study beyond continued scholarly endeavors based on onsite people interaction investigations. This study shall focus on the impacts of communicative e-channels on people interaction. Above all, boosting consumer relationships with service providers could depend on the providers' interactions with consumers at the most appropriate time and place.

The study findings indicate that the social dimension does not represent a significant predictor of total lodging experience. This result is consistent with the study by Papathanassis (2012), which mentions that social functions play a secondary role in services functions in the case of the cruise experience. It is not surprising that social benefits are less critical about other benefits, including friendliness, service, curiosity and information. A hotel is viewed as a private, solitary, exclusive space in which the guests are not inclined to reveal their personal stories. It is important to note that the lodging properties under investigation were business hotels, and the primary purpose of staying at a business hotel may relate to a basic human need (e.g. finding a shelter). However, the guest's desire for social benefits may depend on the characteristics of the hotel (e.g. resort, business and convention), and it may be possible that guests staying at a family-friendly resort hotel would be more eager to pursue social interactions.

\section{Limitations and future suggestions}

Finally, it is critical to consider the limitations of this study. The derived interaction-related benefits are assessed on Chinese guests at upscale city hotels. In other words, considering the potential cultural and language barriers between tourism professionals and foreign guests, this study only focuses on the interaction between native staffs and guests. Therefore, culture and other socioeconomic circumstances may be considered as essential factors impacting the guests' behaviors concerning interaction benefits that are anticipated or sought, where people of different nationalities and backgrounds might impact research outcomes. While this study can shed light on the benefits of people interaction in a hotel setting, it is prudent to evaluate whether the expected benefits may be altered when a different hospitality-related environment is in place. While the focus of the current study is on hotel guests, to future explore the similarities and differences, future research could involve hotel employees. Consequently, future research may look into people interaction benefits in other settings (e.g. theme parks) or groups (e.g. employees).

Moreover, the present study focuses on people interaction in general rather than a specified type of interaction (e.g. guests to guests and guests to residents), so it may be worthwhile to examine further the expected benefits derived from different types of interaction and making comparisons which could add further insights into assist service strategy development. Lastly, in the face of global pandemic COVID-19, social distancing is being followed as one of the effective ways to thwart the spread of the virus. The hotel business is aspiring for alternative ways to stay connected with the guests while implementing reduced human-to-human contact. Thus, it would be imperative to deploy research to find the best solution to enhance the guest's interaction experiences in a postCOVID-19 era.

\section{References}

Armenski, T., Dragičević, V., Pejović, L., Lukić, T. and Djurdjev, B. (2011), "Interaction between tourists and residents: influence on tourism development”, Polish Sociological Review, Vol. 137, pp. 107-118.

\section{People interactions and guest experiences}


IHR

34,2

Bouchet, P., Lebrun, A.M. and Auvergne, S. (2004), "Sport tourism consumer experiences: a comprehensive model", Journal of Sport and Tourism, Vol. 9 No. 2, pp. 127-140.

Brown, T.A. (2006), Confirmatory Factor Analysis for Applied Research, Guilford Publications, New York, NY.

Capistrano, R.C. and Weaver, A. (2018), "That's what friends are for: emotional solidarity, friendship and social interactions between first-generation immigrants and their visiting friends", Journal of Hospitality and Tourism Management, Vol. 36, pp. 57-66.

Carman, J.M. (1990), "Consumer perceptions of service quality: an assessment of the SERVQUAL dimensions"”, Journal of Retailing, Vol. 66 No. 1, p. 33.

Chen, J.S., Prebensen, N. and Uysal, M. (2014), "Dynamic drivers of tourist experiences", in Prebensen, N., Chen, J.S. and Uysal, M. (Eds), Creating Experience Value in Tourism, CABI, Oxfordshire, pp. 11-21.

Chen, J.S., Prebensen, N. and Uysal, M. (2016), “Tourist's experience value and people interaction”", Advances in Hospitality and Leisure, Vol. 12, pp. 169-179.

China Information Center (2015), An Introduction to China's Provinces, Municiplaities and Autonomous Regions, available at: http:/www.china.org.cn/english/features/ProvinceView/ 156519.htm (accessed 10 July 2015).

Choo, H. and Petrick, J.F. (2014), "Social interactions and intentions to revisit for agritourism service encounters", Tourism Management, Vol. 40, pp. 372-381.

Cohen, E. (1979), "Rethinking the sociology of tourism”, Annals of Tourism Research, Vol. 6 No. 1, pp. 18-35.

Creswell, J.W. (1998), Qualitative Inquiry and Research Design: Choosing Among Five Designs, Sage Publication, Thousand Oaks, CA.

Creswell, J.W. (2009), Research Design: Qualitative and Mixed Methods Approaches, Sage Publications, London and Thousand Oaks.

Csikszentmihalyi, M. (1990), "Flow: the psychology of optimal experience”, Harper Collins, Vol. 1, p. 991.

Csikszentmihalyi, M. and LeFevre, J. (1989), "Optimal experience in work and leisure", Journal of Personality and Social Psychology, Vol. 56 No. 5, p. 815.

Czepiel, J.A. (1990), "Service encounters and service relationships: implications for research", Journal of Business Research, Vol. 20 No. 1, pp. 13-21.

Grove, S. and Fish, R. (1997), "The impacts of other customers on service experiences: a critical incident examination of "getting along", Journal of Retailing, Vol. 73 No. 1, pp. 63-85.

Hatcher, L. (1994), A Step-by-Step Approach to Using the SAS System for Factor Analysis and Structural Equation Modeling, SAS, Cary, NC.

Hofstede, G. (1991), Organization and Cultures: Software of the Mind, McGraw Hill, New York, NY.

Huang, J. and Hsu, C.H. (2009), "Interaction among fellow cruise passengers: diverse experiences and impacts", Journal of Travel and Tourism Marketing, Vol. 26, pp. 547-547.

Huang, J. and Hsu, C.H. (2010), "The impact of customer-to-customer interaction on cruise experience and vacation satisfaction", Journal of Travel Research, Vol. 49 No. 1, pp. 79-92.

Kim, J. and Chen, J.S. (2010), "The effect of situational and personal characteristics on consumer complaint behavior in restaurant services", Journal of Travel and Tourism Marketing, Vol. 27, pp. 96-112.

Kim, H. and Chen, J.S. (2019), "The memorable travel expereince and its reminiscience function", Journal of Travel Research, Vol. 58 No. 4, pp. 637-649.

Kim, S., Cha, J., Knutson, B.J. and Beck, J.A. (2011), "Development and testing of the consumer experience Index (CEI)", Managing Service Quality: An International Journal, Vol. 21 No. 2, pp. 112-132.

Kim, J., Ritchie, J.B. and McCormick, B. (2012), "Development of a scale to measure memorable tourism experiences", Journal of Travel Research, Vol. 51 No. 1, pp. 12-25.

Knutson, B.J., Beck, J.A., Kim, S.H. and Cha, J. (2006), "Identifying the dimensions of the experience construct", Journal of Hospitality \& Leisure Marketing, Vol. 15 No. 3, pp. 31-47. 
Kriwoken, L. and Hardy, A. (2018), "Neo-tribes and Antarctic expedition cruise ship tourists", Annals of Leisure Research, Vol. 21, pp. 161-177.

Levy, S. (2010), "Hospitality of the host: a cross-cultural examination of managerially facilitated customer-to-customer interaction”, International Journal of Hospitality Management, Vol. 29, pp. 319-327.

Lin, H., Zhang, M., Gursoy, D. and Fu, X. (2019), "Impact of tourist-to-tourist interaction on tourism experience: the mediating role of cohesion and intimacy", Annals of Tourism Research, Vol. 76, pp. 153-167.

Liu, J.C., Sheldon, P.J. and Var, T. (1987), "Resident perception of the environmental impacts of tourism", Annals of Tourism Research, Vol. 14 No. 1, pp. 17-37.

MacCannell, D. (1973), "Staged authenticity: arrangements of social space in tourist settings", American Journal of Sociology, Vol. 79 No. 3, pp. 589-603.

Mannell, R.C. and Iso-Ahola, S.E. (1987), "Psychological nature of leisure and tourism experience", Annals of Tourism Research, Vol. 14 No. 3, pp. 314-331.

Martin, C.L. (1995), ““The customer compatibility scale: measuring service customers' perceptions of fellow customers"”, Journal of Consumer Studeines and Home Economics, Vol. 19, pp. 299-311.

Martin, C.L. and Pranter, C.A. (1989), "Compatibility management customer-to-customer relationship in service environment", Journal of Service Marketing, Vol. 3, pp. 6-15.

Matteucci, X. (2013), "Photo elicitation: exploring tourist experiences with researcher-found images", Tourism Management, Vol. 35, pp. 190-197.

Meng, F., Tepanon, Y. and Uysal, M. (2008), "Measuring tourist satisfaction by attribute and motivation: the case of a nature-based resort", Journal of Vacation Marketing, Vol. 14 No. 1, pp. 41-56.

Morgan, M. and Xu, F. (2009), "Student travel experiences: memories and dreams", Journal of Hospitality Marketing \& Management, Vol. 18 Nos 2-3, pp. 216-236.

Mossberg, L. (2007), "A marketing approach to the tourist experience", Scandinavian Journal of Hospitality and Tourism, Vol. 7 No. 1, pp. 59-74.

Murphy, L. (2001), "Exploring social interactions of backpackers", Annals of Tourism Research, Vol. 28 No. 1, pp. 50-67.

Otto, J.E. and Ritchie, J. (1996), "The service experience in tourism”, Tourism Management, Vol. 17 No. 3, pp. 165-174.

Papathanassis, A. (2012), "Guest-to-guest interaction onboard cruise ships: exploring social dynamics and the role of situational factors", Tourism Management, Vol. 33 No. 5, pp. 1148-1158.

Parasuraman, A., Zeithaml, V.A. and Berry, L.L. (1988), "Communication and control processes in the delivery of service quality"', Journal of Marketing, Vol. 52 No. 2, pp. 35-48.

Pine, J.B. and Gilmore, J.H. (1999), The Experience Economy, Harvard Business Press, Boston.

Prebensen, N., Chen, J.S. and Uysal, M. (2014), Creating Experience Value in Tourism, CABI, Oxfordshire.

Prentice, R. (2001), "Experiential cultural tourism: museums \& the marketing of the new romanticism of evoked authenticity", Museum Management and Curatorship, Vol. 19 No. 1, pp. 5-26.

Quan, S. and Wang, N. (2004), "Towards a structural model of the tourist experience: an illustration from food experiences in tourism", Tourism Management, Vol. 25 No. 3, pp. 297-305.

Reisinger, Y. and Turner, L. (1998), "Cultural differences between Mandarin-speaking tourists and Australian hosts and their impact on cross-cultural tourist-host interaction", Journal of Business Research, Vol. 42 No. 2, pp. 175-187.

Schmitt, B. (1999), "Experiential marketing”, Journal of marketing management, Vol. 15 Nos 1-3, pp. 53-67. 
Surprenant, C.F. and Solomon, M.R. (1987), "Predictability and personalization in the service encounter", Journal of Marketing, Vol. 51 No. 2, pp. 86-96.

Travel China Guide (2015), Hangzhou Travel Guide, available at: http://www.travelchinaguide.com/ cityguides/hangzhou.htm (accessed 15 April 2015).

Uriely, N., Yonay, Y. and Simchai, D. (2002), "Backpacking experiences: a type and form analysis", Annals of Tourism Research, Vol. 29 No. 2, pp. 520-538.

Volo, S. (2010), "'Bloggers' reported tourist experiences: their utility as a tourism data source and their effect on prospective tourists"”, Journal of Vacation Marketing, Vol. 16 No. 4, pp. 297-311.

$\mathrm{Wu}$, C.H.J. (2007), "The impact of customer-to-customer interaction and customer homogeneity on customer satisfaction in tourism service- the service encounter prospective", Tourism Management, Vol. 28 No. 6, pp. 1518-1528.

Wu, L., Zhang, J. and Chikaraishi, M. (2013), "Representing the influence of multiple social interactions on monthly tourism participation behavior", Tourism Management, Vol. 36, pp. 480-489.

Zhang, J., Inbakaran, R.J. and Jackson, M.S. (2006), ““Understanding community attitudes towards tourism and host-guest interaction in the urban—rural border region"”, Tourism Geographies, Vol. 8 No. 2, pp. 182-204.

\section{Corresponding author}

Joseph Chen can be contacted at: joechen@indiana.edu

For instructions on how to order reprints of this article, please visit our website:

www.emeraldgrouppublishing.com/licensing/reprints.htm

Or contact us for further details: permissions@emeraldinsight.com 